\title{
Copa do Mundo no Brasil: entre expectativas elevadas e benefícios imprecisos
}

\section{World Cup in Brazil: between high expectations and unclear benefits}

\author{
Olga Lúcia Castreghini de Freitas Firkowski (FIRKOWSKI, O. L. C. F.) \\ Patricia Baliski (BALISKI, P.) ${ }^{* *}$ \\ Alexandre Gomes Ferreira (FERREIRA, A. G.) ${ }^{* * *}$
}

\begin{abstract}
RESUMO - No presente texto discutem-se os megaeventos esportivos e a sua importância como estratégia de desenvolvimento urbano. A Copa do Mundo de Futebol da FIFA de 2014 é o objeto de análise, com a ênfase voltada para a cidade de Curitiba. São apresentados dados relativos aos investimentos públicos nas 12 cidades-sedes. Sob esta ótica se faz uma avaliação dos setores de mobilidade urbana, infraestrutura de aeroportos e de portos, da construção e/ou reforma de estádios, e de desenvolvimento turístico. Como fonte principal de informações foi utilizada a Matriz de Responsabilidades do Governo Federal e, para Curitiba, utilizaram-se também dados dos órgãos públicos locais. Em Curitiba partiu-se de uma ampla agenda de transformações urbanas previstas em 2009 para realizar em 2014, de reduzidas intervenções urbanas, com impactos limitados no conjunto da cidade, corroborando o hiato entre as expectativas criadas e os benefícios advindos com a realização de megaeventos.
\end{abstract}

Palavras chave: Copa do Mundo; Megaevento; Transformações urbanas; Curitiba.

ABSTRACT - This text presents a view on mega sporting events and their relevance as urban developing strategy. Fifa's 2014 World Cup is the analysis object, focusing Curitiba host-city. It is presented data related to the public investments directed in the 12 host-cities. From this perspective it makes an assessment of urban mobility sectors, airports and ports infrastructures, in stadium building or adaptation according to Fifa's criteria, and in tourism infrastructure. Data used for this analysis are available in the Matriz de Responsabilidades do Governo Federal (Federal Government Responsibility

\footnotetext{
Formação: Graduação em Geografia pela Universidade Estadual Paulista (UNESP), campus de Presidente Prudente (SP), Mestrado em Geografia pela UNESP, campus de Rio Claro (SP), Doutorado em Geografia Humana pela Universidade de São Paulo (USP), Pós-doutorado pela Université Paris I, França. Atividade profissional: Professora do Departamento de Geografia da Universidade Federal do Paraná (UFPR). Pesquisadora do Conselho Nacional de Desenvolvimento Científico e Tecnológico (CNPQ) e do INCT/Observatório das Metrópoles, Departamento de Geografia. Endereço: UFPR - Av. Francisco H. dos Santos s./n. - Centro Politécnico, Jardim das Américas. CEP: 81531-990 - Curitiba - Paraná (Brasil). Telefone: 41 3361-3454. E-mail: olgafirk@ufpr.br

** Formação: Graduação e Mestrado em Geografia pela UFPR. Atividade profissional: Assistente de Pesquisa do Núcleo Curitiba do INCT/Observatório das Metrópoles, Laboratório de Dinâmicas Metropolitanas. Endereço: UFPR - Av. Francisco H. dos Santos s/n - Centro Politécnico, Jardim das Américas. CEP: 81531-990 - Curitiba - Paraná (Brasil). Telefone: 41 3361-3454. E-mail: pbaliski@gmail.com

* Formação: Graduação e Mestrado em Geografia pela UFPR Atividade profissional: Laboratório de Dinâmicas Metropolitanas. Endereço: UFPR - Av. Francisco H. dos Santos s/n - Centro Politécnico, Jardim das Américas. CEP: 81531-990 - Curitiba - Paraná (Brasil). Telefone: 41 3361-3454. E-mail: alegfm@hotmail.com
} 
Matrix). And about Curitiba were used data from local public instances. For the case of Curitiba, it was used a wide expected interventions and transformations stated in 2009 to be accomplished until 2014, from reduced urban interventions, with limited impacts for the city, corroborating the gap between expectations and the benefits came from the holding mega events.

Key words: World Cup; Mega event; Urban transformations; Curitiba. 


\section{INTRODUÇÃO}

A apreensão do fenômeno urbano na atualidade emerge como uma tarefa complexa a todos os pesquisadores que se propõem a fazê-lo. A realidade, que se conforma e agrega novos elementos a cada momento, repercute em uma série de situações inexistentes nas décadas passadas e ao mesmo tempo abre novas possibilidades de reflexão. Neste contexto, vários desafios se impõem, sejam ao planejamento, à gestão ou ao cotidiano das pessoas nos centros urbanos, fatos que determinam a frequente busca por soluções de novos e também velhos problemas. As cidades passaram a ser pensadas e produzidas com o objetivo de torná-las protagonistas da dinâmica econômica, por meio da adequação de suas formas de gestão e produção. Competitividade, empresariamento urbano (HARVEY, 1996), planejamento estratégico (por projetos), intervenções pontuais, entre outros enunciados, passam a compor o rol das iniciativas a serem adotadas pelos gestores urbanos.

É nesse sentido que, nas últimas décadas, em um período de internacionalização e competição entre cidades, cresce a busca por novos investimentos ligados ao capitalismo cognitivo (ASCHER, 2010) e emerge a ideia de que megaeventos esportivos, com destaque para Jogos Olímpicos e Copa do Mundo, podem servir como motores do desenvolvimento, principalmente quando viabilizados por meio de intervenções urbanas, transformando-os em estratégia para governos e promotores urbanos que buscam empreender e justificar a renovação de algumas porções territoriais em um curto espaço de tempo.

O Brasil será a sede de dois dos maiores megaeventos esportivos da atualidade: a Copa do Mundo de Futebol da FIFA em 2014 e as Olimpíadas em 2016, razão pela qual o tema ganha destaque não apenas nos meios político e empresarial, como também no acadêmico.

Nesse contexto, no presente artigo o objetivo é analisar a temática dos megaeventos esportivos, contextualizando sua importância enquanto estratégia de desenvolvimento urbano e inserindo elementos referentes à discussão sobre o processo de preparação da Copa do Mundo de Futebol da FIFA de 2014, em Curitiba, considerando as possíveis repercussões do evento e seus supostos legados. 
Inicialmente, são apresentadas informações sobre os investimentos previstos para as 12 cidades-sede, pelos respectivos estados e governo federal vinculados à implantação de infraestrutura para mobilidade urbana, aeroportos e portos, construção e/ou reforma de estádios, além de desenvolvimento turístico. Como fonte principal de informações foi utilizada a Matriz de Responsabilidades do Governo Federal (CGU, 2012) ${ }^{1}$ e, para Curitiba, utilizaram-se também dados dos órgãos públicos locais.

As 12 cidades-sede do evento no Brasil são: Curitiba e Porto Alegre, na região Sul; Belo Horizonte, Rio de Janeiro e São Paulo, na região Sudeste; Brasília e Cuiabá, na região Centro-Oeste; Manaus, na região Norte; e Fortaleza, Natal, Recife e Salvador, na região Nordeste. Portanto, a análise considerou todas estas cidades e a distribuição dos investimentos totais e por setores. Tal modelo descentralizado de realização dos jogos e dos investimentos reacende os debates sobre a questão regional, além da urbana, e sobre o potencial dos mesmos em contribuir para a superação ou reafirmação das desigualdades regionais existentes no Brasil.

\section{OS MEGAEVENTOS E AS NOVAS CONFIGURAÇÕES DO URBANO}

Apesar de utilizarem conceitos distintos, autores como Harvey (2011), Ascher (2010), Logan e Molotch (1996) convergem sobre a possibilidade de se delinear um período, ou melhor, um recorte espaço-temporal em que transformações na estrutura capitalista ${ }^{2}$ indicariam um novo momento, capaz de proporcionar mudanças importantes na forma como as cidades são governadas. Tal processo teria como marco a década de 1970, e como centro de difusão, os Estados Unidos e, a partir daí, se propagado para o resto do mundo, com intensidade variável, mas fundamentalmente sob os ditames das políticas neoliberais de Washington. Tais pressupostos tinham como um de seus carroschefe a desrregulamentação nacional e internacional das operações financeiras

\footnotetext{
${ }^{1}$ As informações existentes na Matriz de Responsabilidades podem ser acessadas no seguinte endereço eletrônico: http://www.portaltransparencia.gov.br/copa2014/home.seam.

${ }^{2}$ Embora sob perspectivas distintas, enquanto Harvey (2011) trata da contrarrevolução capitalista ou o ponto de inflexão, Ascher (2010) prefere denominar de capitalismo cognitivo e Logan e Molotch (1996) denominam de máquina de crescimento, referindo-se aos processos de transformação que têm como marco a década de 1970 e trazem implicações significativas para as cidades contemporâneas.
} 
culminando com a abertura do mundo para a competição internacional intensificada (HARVEY, 2011).

Desde então, tem-se uma dinâmica econômica sustentada em dois pilares: primeiro, a liberalização postulada pelo ajuste estrutural; segundo, um novo paradigma técnico-científico, estruturado em torno de novas tecnologias da informação e comunicação. Com esta base, torna-se possível afimar que a partir do final dos anos de 1970, começou-se a perceber uma dinâmica da economia global substancialmente diferente da fase anterior.

Tal processo impulsionou uma crescente dissociação das cidades em relação aos Estados Nacionais de que fazem parte, na medida em que os gestores das mesmas forçosamente passaram a assumir uma maior responsabilidade com o seu crescimento econômico, num contexto de escassez de transferência de recursos, levando à expectativa de que uma cidade empresarial vai competir como um ator econômico relativamente independente, no mercado por capital e trabalho.

A perspectiva de que megaeventos podem servir como motores do desenvolvimento pode ser melhor compreendida sob tal prisma. Para Andranovich, Burbank e Heying (2001, p. 114) é possível identificar uma grande estratégia de megaeventos neste cenário, que para os autores foi capaz de gerar um novo ordenamento urbano voltado para as demandas de corporações, indústrias de alta tecnologia e produtores de serviços cada vez mais sofisticados.

Num contexto de escassez de investimentos, a capacidade adaptativa e a flexibilização passaram a ser características necessárias às cidades para que, de forma célere, transformações urbanas fossem efetivadas e para que tais cidades ganhassem visibilidade e notoriedade dentro de um certo escopo de pensamento que lhes garantiriam um 'selo de qualidade', atestando que estão aptas a concorrer no mercado mundial de cidades.

Sánchez (2010) referindo-se a este processo o denomina como 'reinvenção das cidades' ao qual sua nova inscrição mundial por via dos projetos associados aos megaeventos gerou um modelo de cidade e de urbanismo de resultados marcadamente acentuadores das desigualdades, pois, ao mesmo tempo em que espaços são renovados em ritmo intenso e a prazo fixo, as receitas públicas e as políticas sociais ficam diretamente comprometidas, favorecendo a multiplicação dos conflitos. 
Surgem neste contexto, novos nichos de consumo e estilo de vida individualizados, "contruídos em torno de um estilo pós moderno de urbanização, como a disneyficação dos centros das cidades", impulsionadores de intensos processos de gentrificação (HARVEY, 2011, p. 11).

Queirós (2010), em uma análise crítica dos rumos do urbanismo em Barcelona, indica que as intervenções realizadas a partir dos anos 2000 não resultaram do consenso e do debate público, sendo privilegiados os grandes projetos, associados a operações controladas por empresas privadas. O princípio inicial sucumbe aos grandes grupos imobiliários privados e os objetivos das políticas urbanas denotam terem se reduzido a facilitadores do investimento das empresas na aceleração de determinados processos de mercantilização. Questionando-se sobre a quem são dirigidas as ações estratégicas de Barcelona na atualidade, a autora não tem dúvidas em responder: às elites, aos jovens qualificados e aos turistas (QUEIRÓS, 2009).

Sob a mesma perspectiva, Logan e Molotch (1996), afirmam que existem agentes poderosos na condução das coalizões entre setores privados e o poder público para conformar as políticas urbanas em torno de um consenso de crescimento tomado como um objetivo inquestionável de modernização e sucesso das cidades.

Pode-se argumentar que os megaeventos, assim como os projetos urbanos associados a eles, efetivamente são dirigidos por coalizões de atores (governamentais, privados e de agências internacionais) vinculados a um projeto que de forma muito clara é utilizado para a criação de um espetáculo em escala mundial, cujo objetivo é chamar para si a atenção internacional, redirecionar investimentos e "amalgamar um novo projeto hegemônico" (SÁNCHEZ, 2010, p. 110).

Para Vainer (2011), trata-se de uma nova forma de governar e interpretar as cidades, em que as relações entre interesses privados e Estado se reconfiguram completamente e entronizam novas modalidades de exercício hegemônico. Em tal contexto, torna-se regra a invisibilização dos processos decisórios, em razão mesmo da desqualificação da política e da desconstituição de fato das formas "normais" de representação de interesses. "Não se sabe onde, como, quem e quando se tomam as decisões - certamente não nas instâncias formais em que elas deveriam ocorrer nos marcos republicanos" (VAINER, 2011, p. 11). 
Tal situação se explica porque as intenções das classes rentistas se harmonizam com as necessidades do poder público, ambas interessadas no consenso pelo "crescimento". Esta é a essência da questão: a "máquina de crescimento" é antes de tudo um fantástico instrumento de canalização dos fundos públicos em favor de uma apropriação privada dos ganhos que o espaço propicia (LOGAN; MOLOTCH, 1996).

\section{LIÇÕES DE GRANDES GASTOS E BENEFÍCIOS IMPRECISOS}

Sendo então os megaeventos uma nova referência ao modelo das cidades que competem entre si no mercado global para atrair investimentos e turistas, têm-se nos Jogos Olímpicos e Copas do Mundo os exemplos mais conhecidos e desejados pelos gestores urbanos que buscam destacar as cidades sob sua administração como protagonistas em um mundo globalizado.

Esses esforços muitas vezes se tornam parte de amplos projetos de revitalização e podem incluir a construção de centros de convenções e hotéis, campanhas públicas de segurança, regulação da atividade econômica informal e modernização da infraestrutura. Inevitavelmente emerge, em meio a esta disputa, a discussão sobre a relação custobenefício de realizá-los. Uma análise pormenorizada da literatura sobre o assunto exibe muitas dúvidas quanto aos ganhos por sediar megaeventos esportivos.

De acordo como Baade e Matheson (2004), uma grande firma norte americana de consultoria, AECOM (Architectural Engineering, Consulting, Operations and Maintenance), a Copa do Mundo de 1994, realizada nos Estados Unidos, deveria arrecadar 4 bilhões de dólares, porém um estudo posterior mostrou que o custo para a viabilidade do evento nas cidades-sede americanas ultrapassou em muito a perspectiva arrecadatória, chegando a 9,26 bilhões de dólares.

De forma sintética, em contraste com os relatórios de impacto econômico anteriores, que sugeriram um grande aumento no emprego devido ao torneio, seu estudo posterior, não encontrou nenhum incremento significativo sobre o mesmo nas cidades e suas regiões. Ainda segundo essa fonte, é possível destacar que a mesma análise em setores específicos da economia além de não encontrar benefícios dos jogos em relação ao emprego na área de serviços, identificou um impacto significativamente negativo 
sobre o emprego no comércio varejista, atribuindo tal situação ao 'efeito crowding-out', ou de deslocamento, relacionado ao endividamento público comumente necessário para viabilizar megaeventos. (BAADE; MATHESON, 2004).

Reportagem exibida no canal CNN (VOIGT, 2010) detalhou como a Copa do Mundo de Futebol da FIFA realizada no Japão/Coreia do Sul em 2002, tornou-se um grande empecilho econômico às comunidades locais. Além de não alcançar os resultados esperados, a manutenção dos estádios construídos para os jogos tem custo muito superior às receitas auferidas. Em oito dos dez estádios construídos ou renovados no Japão para a realização da Copa, são necessários entre 3 e 6 milhões de dólares por ano para a manutenção, saldo que é captado pelos contribuintes japoneses. Segundo dados apresentados por Voigt (2010), só o estádio construído na cidade de Saitama, tem um custo anual de manutenção de cerca de 2,5 milhões de dólares aos cofres públicos locais.

A Copa do Mundo realizada em 2006 na Alemanha foi amplamente divulgada como um grande sucesso. Meaning (2007), demonstra, porém, por meio de uma análise detalhada em setores da economia, que seus impactos não foram tão significativos quanto o divulgado.

Uma comparação dos balanços de turismo, por exemplo, para os meses de maio a julho de 2006, período de realização do evento, tem como resultado a redução de aproximadamente 324 milhões de euros neste setor (MEANING, 2007). Ao longo de todo o ano de 2006, houve uma melhoria geral líquida de apenas 60 milhões de euros, em comparação com o ano anterior, um montante que em termos da economia total é insignificante, seja qual for a perspectiva considerada, principalmente a um país como a Alemanha (MEANING, 2007).

No que tange à criação de empregos, Meaning (2007) utiliza relatórios da agência nacional de trabalho alemã que demonstram a criação de 25.000 a 50.000 novos postos de trabalho decorrentes da Copa do Mundo, destacando, porém, que sua maioria foi de natureza temporária, comparado ao mercado total de empregos formais, cerca de 40 milhões, este valor corresponde a um aumento entre $0,06 \%$ e $0,13 \%$. Além de muito pouco significativo, o autor adverte que este aumento no emprego pode ter ocorrido não necessariamente em função da Copa do Mundo, devendo ser ajustado em um contexto de tendência ao emprego que, em geral no ano de 2006, foi claramente positivo. Tal 
tendência fica evidente ao se perceber que ao longo de 2006 todos os meses do ano obtiveram números de emprego que ultrapassaram os correspondentes aos meses do ano anterior (MEANING, 2007).

De todos os casos recentes, talvez o da Copa do Mundo de Futebol da FIFA 2010, na África do Sul, seja o mais significativo, quando se leva em consideração que os impactos sociais da destinação de vultosas quantias de dinheiro público à realização do evento podem se revelar problemáticos à população local.

Embora muito se tenha especulado - principalmente as grandes empresas de consultoria -, sobre os benefícios da realização da Copa do Mundo de Futebol da FIFA 2010, na África do Sul, para Cottle (2011) é muito claro que o mundial "chegou" e "se foi”, deixando muitas decepções aos habitantes sul-africanos, quando voltaram às suas vidas cotidianas imediatamente após o evento. Em oposição a dificuldade de mensuração dos legados tangíveis, principalmente os econômicos e esportivos, sobraram justificativas dos benefícios intangíveis, como o suposto forjamento de uma coesão identitária nacional com a venda da imagem positiva do país para o mundo, ainda segundo Cottle (2011), um momento fugaz e muito mais mítico do que prático.

Em valores globais, Bond e Cottle (2011), apontam que o total de custos para realização da Copa do Mundo de Futebol da FIFA 2010 foi de aproximadamente R \$,4 bilhões de dólares.

O total do impacto na economia sul-africana (diretos e indiretos) foi estimado em 12,4 bilhões de dólares, sendo $63 \%$ deste valor antes do evento e $38 \%$ durante o ano de 2010 (GRANT THORNTON, 2010), apesar disso, a contribuição econômica líquida para o Produto Interno Bruto - PIB do país em 2010 foi de apenas 0,54\%. Em contraste com este valor, Amato (2010) afirma que a HSRC (Human Science Research Council), agência de pesquisa sul-africana, limitou ainda mais a contribuição da Copa ao PIB do país, algo entre $0,2 \%$ e $0,3 \%$, muito abaixo das previsões iniciais da FIFA e empresas de consultoria que chegaram a supor uma margem de $3 \%$.

Quando se analisa o aumento dos valores despendidos com a construção dos estádios torna-se ainda mais evidente o impacto dos mesmos para os investimentos totais realizados no mundial e consequentemente os lucros obtidos pelas empresas que os construíram. Assim, segundo Taal (2011), a diferença entre o custo estimado para a construção dos estádios na África do Sul no período 2003/2010, teve uma variação 
superior a $1100 \%$. Quase a metade de todo o investimento destinado a infraestruturas, aproximadamente 5,2 bilhões de dólares, foi gasto com os estádios (TAAL, 2011), levando ao questionamento, sobre como tais investimentos poderiam trazer ganhos à população em geral, em particular num país no qual o futebol não é o esporte preferido da população.

É fundamental registrar que existem diferenças marcantes de perspectiva entre o significado do custo necessário a realização de eventos deste tipo para países desenvolvidos, de um lado, e emergentes ou subdesenvolvidos, de outro, com um comprometimento de recursos proporcionalmente maior para estes em relação aos primeiros, na medida em que o custo do capital é maior nos países subdesenvolvidos e o "dinheiro gasto no evento é dinheiro não gasto em outras obras", ao mesmo tempo em que o custo do trabalho também é menor, em razão de que os salários são mais baixos, assim como os custos operacionais e de infraestrutura (BETARELLI JR; DOMINGUES; MAGALHÃES, 2011, p. 410).

\section{A DISTRIBUIÇÃO REGIONAL E SETORIAL DOS INVESTIMENTOS NO BRASIL}

$\mathrm{Na}$ busca por elevadas somas de recursos financeiros, decorrentes dos investimentos necessários, e pela visibilidade internacional potencializada pelo mundial, vários gestores de cidades brasileiras protocolaram suas candidaturas para receber os jogos da Copa do Mundo de Futebol da FIFA 2014. Dentre as dezessete cidades que se candidataram, doze foram escolhidas e estão distribuídas pelas cinco grandes regiões brasileiras, no entanto, com nítida concentração nas regiões Sudeste e Nordeste. Somente nestas duas regiões, estão localizadas sete cidades-sede do mundial.

Além da concentração das cidades escolhidas em determinadas regiões, outra questão que perpassa as discussões, é a diferença no total de investimentos por cidadesede. Como pode ser observado na figura 1 , os investimentos são bastante díspares, com evidente concentração na região Sudeste. 
FIGURA 1 - BRASIL: TOTAL DE INVESTIMENTOS POR CIDADE-SEDE DA COPA 2014, NOVEMBRO DE 2012.

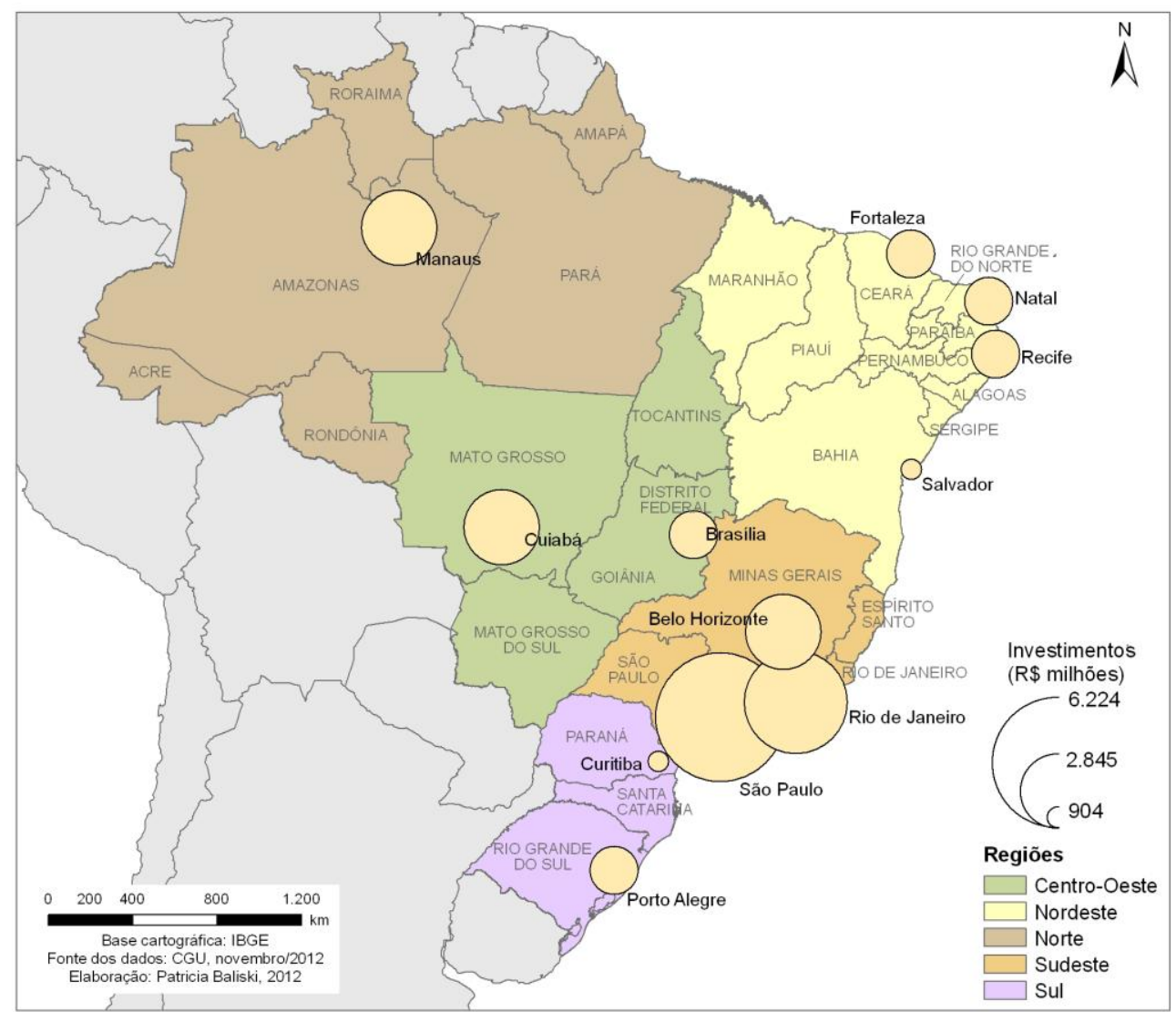

Fonte: CGU (2012) - Matriz de Responsabilidades/Controladoria-Geral da União.

De acordo com os dados da Matriz de Responsabilidades, somente as três cidades-sede localizadas na região Sudeste, respondem por $46,71 \%$ dos investimentos destinados às obras da Copa, ou seja, R\$ 12.838,06 milhões ${ }^{3}$, envolvendo estádios, mobilidade urbana, aeroportos, desenvolvimento turístico e em alguns casos, portos. Nesse sentido, diferentemente do apresentado pelos governantes, de que a descentralização dos jogos favoreceria a distribuição das possíveis oportunidades advindas com a Copa para as diferentes regiões do Brasil, o que se observou, de fato, é o reforço da concentração, na medida em que os estados de São Paulo, Rio de Janeiro e Minas Gerais, nos quais estão as cidades-sede da região Sudeste, são responsáveis por 53,1\% do PIB - Produto Interno Bruto (IBGE, 2013a). Considerando apenas os municípios, São Paulo, Rio de Janeiro e Belo Horizonte, ocupam, respectivamente, a $1^{\text {a }}$, $2^{\mathrm{a}}$ e $5^{\mathrm{a}}$ posição entre aqueles com maior PIB no Brasil (IBGE, 2013b).

\footnotetext{
${ }^{3}$ US\$ 6.176.004.233,42 (cotação do dia 26 de novembro de 2012 / US\$ 1 = R\$ 2,0787).
} 
Em se tratando dos investimentos por setor (TABELA 1), as obras de mobilidade urbana se sobressaíram, na medida em que representavam 43,97\% do total. Com maior participação nesses recursos, destacam-se as cidades de Rio de Janeiro, São Paulo e Manaus que, conjuntamente, receberiam 46,42\% dos recursos previstos para mobilidade. A grande participação decorre de obras de elevados custos, como o BRT Transcarioca (Aeroporto/Penha/Barra), no Rio de Janeiro, com valor estimado em R\$ 1.883,60 milhões; o Monotrilho - Linha 17 - Ouro, em São Paulo, orçado em R\$ 1.881,50 milhões; e Monotrilho Linha Norte-Centro, em Manaus, estimado em R\$ 1.844,90 milhões. Somente estas três obras representariam quase a metade dos investimentos em mobilidade para as doze cidades-sede ${ }^{4}$.

TABELA 1 - INVESTIMENTOS ASSEGURADOS PELA MATRIZ DE RESPONSABILIDADES, POR CIDADE-SEDE E SETOR (R\$ MILHÕES)

\begin{tabular}{lc|c|c|c|c|c}
\hline \multicolumn{1}{c|}{ Cidade-sede } & Aeroporto & $\begin{array}{c}\text { Arena/Estádi } \\
\text { o }\end{array}$ & $\begin{array}{c}\text { Desenvolvimen } \\
\text { to turístico }\end{array}$ & $\begin{array}{c}\text { Mobilidade } \\
\text { Urbana }\end{array}$ & Porto & Total \\
\hline Belo Horizonte & 508,65 & 695 & 6,3 & 1391,2 & - & 2601,15 \\
Brasília & 651,04 & 812,2 & 3,9 & 103,1 & - & 1570,24 \\
Cuiabá & 91,31 & 518,9 & 3,6 & 1453,5 & - & 2067,31 \\
Curitiba & 84,49 & 234 & 9,4 & 576,7 & - & 904,59 \\
Fortaleza & 349,8 & 518,6 & 22,1 & 562 & 149 & 1601,5 \\
Manaus & 394,12 & 515 & 2,04 & 1844,9 & 89,4 & 2845,46 \\
Natal & 557,84 & 417 & 28,3 & 661,8 & 53,7 & 1718,64 \\
Porto Alegre & 579,27 & 330 & 12,8 & 870,9 & - & 1792,97 \\
Recife & 18,47 & 500,2 & 47,7 & 856,9 & 25,7 & 1448,97 \\
Rio de Janeiro & 813,27 & 808,4 & 193,4 & 1883,6 & 314 & 4012,67 \\
Salvador & 47,61 & 591,7 & 22,1 & - & 36 & 697,41 \\
São Paulo & 3258,04 & 820 & 29,7 & 1881,5 & 235 & 6224,24 \\
TOTAL & $\mathbf{7 3 5 3 , 9 1}$ & $\mathbf{6 7 6 1}$ & $\mathbf{3 8 1 , 3 4}$ & $\mathbf{1 2 0 8 6 , 1}$ & $\mathbf{9 0 2 , 8}$ & $\mathbf{2 7 4 8 5 , 1 5}$ \\
\hline
\end{tabular}

Fonte: CGU (2012) - Matriz de Responsabilidades/Controladoria-Geral da União.

Outro setor de destaque na destinação dos recursos (Tabela 1) é o de aeroportos, para o qual foram previstos $26,76 \%$ do montante total dos investimentos da Copa do Mundo de Futebol da FIFA 2014 (CGU, 2012). Ressalta-se a distribuição altamente concentrada dos investimentos neste setor, somente a cidade de São Paulo receberia 44,3\% dos recursos destinados aos aeroportos, em contraposição, as cidades de Recife e Salvador receberiam menos de $1 \%$ do total.

\footnotetext{
${ }^{4}$ Embora nestas cidades estejam os projetos de mobilidade de custo mais elevados, em outras, alguns projetos também demandariam grande volume de recursos, como é o caso do VLT Cuiabá/Várzea Grande, em Cuiabá, orçado em mais de R\$ 1 bilhão (CGU, 2012).
} 
O terceiro setor mais representativo na recepção de recursos foi o da construção de estádios/arenas. Tais investimentos garantiram as obras de: i) reforma dos estádios/arenas pré-existentes, em Curitiba, Rio de Janeiro, Belo Horizonte, Porto Alegre e Fortaleza; ii) demolição da estrutura anterior e construção de uma nova no mesmo local, em Manaus, Natal, Salvador, Brasília e Cuiabá; iii) implantação do estádio/arena em uma nova localização, como ocorreu em São Paulo e Recife. Ressaltase que os estádios/arenas de Brasília, Rio de Janeiro e São Paulo foram responsáveis por inversão de recursos superiores a $\mathrm{R} \$ 800$ milhões cada (Tabela 1).

No entanto, além dos elevados investimentos a serem feitos em todas as cidades para a construção de estádios/arenas, outra questão de destaque se refere ao fato de haver em algumas cidades-sede, incipiente ou nula inserção de equipes de futebol local nas categorias principais dos campeonatos nacionais, evidenciando que tais equipamentos ficarão ociosos no período pós-Copa. Considera-se que a viabilidade econômica e a manutenção de estádios dependem, em grande parte, da existência de equipes de futebol com alta capacidade de atração de público.

Dentre as 12 cidades-sede, Cuiabá, Manaus, Natal e Brasília não possuem equipes de futebol que disputam a Série A do campeonato nacional, enquanto Cuiabá tem a equipe de mesmo nome competindo pela Série C, Brasília tem o Brasiliense competindo pela Série D e apenas Natal possui duas equipes competindo na Série B: ABC e América (CBF, 2013).

Portanto, é difícil imaginar que a média de público nesses estádios/arenas será capaz de se aproximar da capacidade efetiva dos mesmos, que varia entre 40 e 70 mil lugares, conforme determina a FIFA (FIFA, 2011).

Em relação aos setores de desenvolvimento turístico (criação de centros de atendimento ao turista, sinalização turística e hotelaria) e portos, constatou-se montantes de investimentos bem menores, afinal, receberiam, respectivamente, $1,39 \%$ e $3,28 \%$ do total (CGU, 2012). Do mesmo modo que nos demais setores, os maiores investimentos concentram-se na região Sudeste, com destaque para Rio de Janeiro e São Paulo, principalmente em relação aos portos. Em se tratando do desenvolvimento turístico, destaca-se o Rio de Janeiro, com 50,72\% dos recursos previstos para este segmento.

Além dos elevados custos de obras específicas e da concentração dos maiores investimentos em determinadas cidades-sede, outro ponto a ser ressaltado é o aumento 
constante do montante dos investimentos previstos. Considerando apenas as obras de mobilidade urbana, aeroportos, portos e estádios, os investimentos chegaram, em agosto de 2012, a R\$ 27.416 milhões $^{5}$. Esses dados distinguem-se sobremaneira dos apresentados em agosto de 2011, quando o valor estimado das obras era de R\$ 23.358,40 milhões (CGU, 2012). Os principais setores responsáveis pela ampliação dos investimentos foram os aeroportos ( $\mathrm{R} \$ 2.183$ milhões - 42,36\%) e os estádios ( $\mathrm{R} \$$ 1.054 milhões-18,46\%), setores tidos como os mais importantes pela FIFA.

Considerando-se o aumento dos investimentos por cidade, apresentados na Matriz de Responsabilidades para os anos de 2011 e 2012 (CGU, 2011; 2012), constatou-se que em várias delas, os percentuais foram acima de $10 \%$ no período, apenas três tiveram redução de custos e em cidades como Natal, Porto Alegre, São Paulo e Rio de Janeiro ocorreu uma ampliação de mais de $\mathrm{R} \$ 600$ milhões. O caso mais extremo foi o da cidade de Cuiabá, para a qual, no período de um ano, os custos se ampliaram em mais de $\mathrm{R} \$ 1$ bilhão. Tal aumento ocorreu em função da mudança dos projetos de mobilidade, em especial a inserção do VLT Cuiabá-Várzea Grande, orçado em R \$ 1.261,6 milhões mas que, contudo, não implantado em tempo hábil para a Copa.

Ainda segundo a mesma fonte (CGU, 2011; 2012), em relação às cidades que apresentaram diminuição nos investimentos entre agosto de 2011 e agosto de 2012, o percentual mais significativo foi em Salvador, na qual se verificou a redução de mais de R \$ 500 milhões. Tal situação decorreu da retirada do BRT (Bus Rapid Transit): Corredor Estruturante Aeroporto/Acesso Norte dos projetos para a Copa 2014, orçado inicialmente em $\mathrm{R} \$ 567,7$ milhões.

\section{A LIMITADA REPERCUSSÃO ESPACIAL DOS PROJETOS EXECUTADOS EM CURITIBA}

Em Curitiba, os investimentos programados como obras preparatórias para a Copa do Mundo de 2014 sofreram diversas transformações desde 2009, quando a cidade foi escolhida como uma das doze cidades-sede. Sua candidatura baseou-se na

\footnotetext{
${ }^{5} \mathrm{O}$ valor apresentado distingue-se do existente na Tabela 1, pois os relatórios de acompanhamento do Tribunal de Contas da União (TCU, 2011 e 2012), não consideraram em suas análises os investimentos em desenvolvimento turístico, além da data de referência das duas fontes ser diferente.
} 
apresentação de uma proposta audaciosa que envolvia muitos projetos de infraestrutura para a cidade, em especial no âmbito da mobilidade urbana.

Uma das primeiras intervenções anunciadas foi a implantação do metrô e a expectativa era de que, além da visibilidade internacional, grandes transformações urbanas ocorreriam na cidade. Levantamento realizado por Araújo (2009), apontava a existência de dezessete projetos ligados à mobilidade, dentre eles, o Anel Ferroviário, a terceira pista do aeroporto Afonso Pena e o Corredor Metropolitano, seriam os com maior impacto no espaço metropolitano.

De todos os projetos previstos, muitos foram excluídos antes mesmo da assinatura da Matriz de Responsabilidades, acordo entre Governo Federal e entes envolvidos (município e estado). Assim, do total de projetos previstos e orçados em aproximadamente R $\$ 9$ bilhões, após a assinatura da Matriz, em 2010, chegou-se a um montante de $\mathrm{R} \$ 705,39$ milhões, investimento modesto quando se considera a projeção inicial de gastos. Destaca-se ainda que, mesmo no conjunto de projetos assegurados pela Matriz, houve também aqueles que foram excluídos posteriormente, como o Corredor Metropolitano, obra que propiciaria a integração viária entre sete municípios da Região Metropolitana de Curitiba (RMC), e o BRT: Avenida Cândido de Abreu, que previa a requalificação do Centro Cívico de Curitiba. Os dois casos foram excluídos principalmente em razão do aumento excessivo dos investimentos previstos ${ }^{6}$.

Com isso, as expectativas iniciais foram paulatinamente reduzidas e prevaleceu um conjunto de transformações pontuais, conforme pode ser visualizado na figura $2 \mathrm{e}$ no quadro 1 , que confere a Curitiba a menor participação no total de investimentos para a Copa do Mundo 2014, apenas 4,2\% do total das cidades-sede ${ }^{7}$.

\footnotetext{
${ }^{6}$ O Corredor Metropolitano devido a modificações no projeto original teve seu custo previsto ampliado de R \$ 137,6 milhões para R \$ 427,5 milhões (TCU, 2012). Já o Corredor da Avenida Cândido de Abreu, de R \$ 5,1 milhões para R \$ 26 milhões (MIKOS, 2013).

${ }^{7}$ De acordo com as informações existentes no anexo 2 da Resolução GECOPA no 25 , de 25 de novembro de 2013 (BRASIL, 2013). No cálculo foram excluídas as ações de telecomunicações e segurança, pois os investimentos não estão especificados por cidade-sede.
} 
FIGURA 2 - OBRAS DE MOBILIDADE URBANA PREVISTAS NO ÂMBITO DA COPA DO MUNDO 2014 EM CURITIBA E ENTORNO METROPOLITANO (2009, 2011 E 2013).

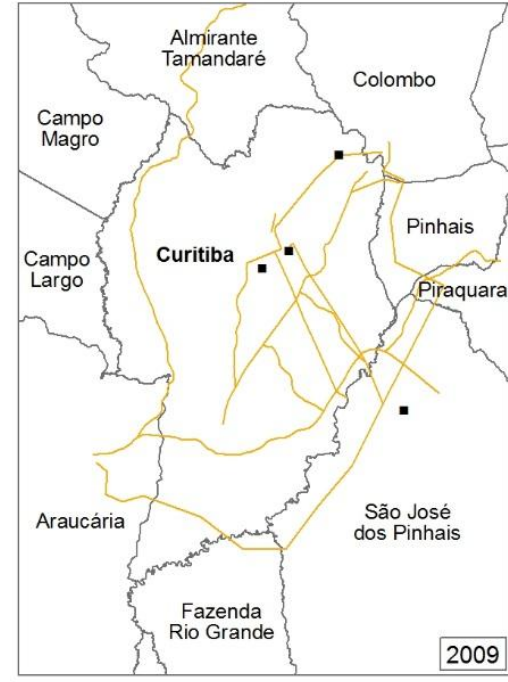

- Projetos de intervenção - Copa do Mundo 2014
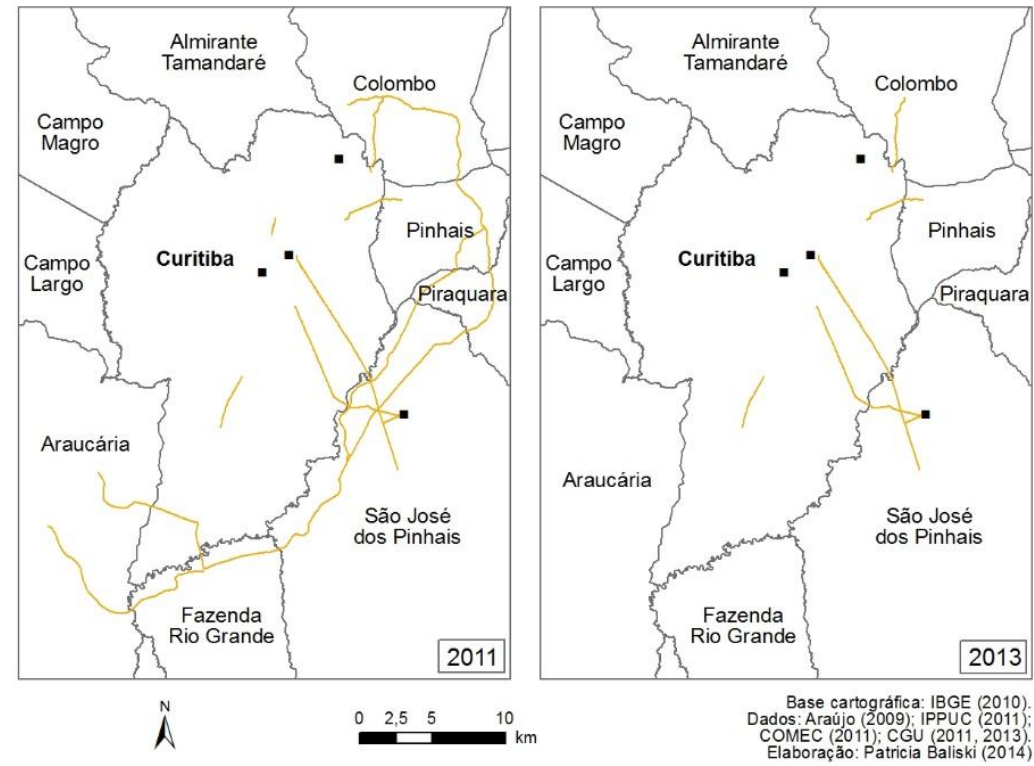

QUADRO $1-$ CURITIBA: PROJETOS ASSEGURADOS PELA MATRIZ DE RESPONSABILIDADES, 2013.

\begin{tabular}{|c|c|c|}
\hline Tema & Projeto & Descrição \\
\hline \multirow{3}{*}{ Aeroporto } & Pistas de Pouso e Decolagem e de Táxi & $\begin{array}{l}\text { Restauração das Pistas de Pouso e Decolagem e de } \\
\text { Táxi e obras complementares. }\end{array}$ \\
\hline & Pátio de Aeronaves & $\begin{array}{l}\text { Ampliação do pátio, infraestrutura, } \\
\text { macrodrenagem e obras complementares. }\end{array}$ \\
\hline & $\begin{array}{l}\begin{array}{l}\text { Terminal de } \\
\text { Viário }\end{array} \\
\text { Passageiros e }\end{array}$ & $\begin{array}{l}\text { Ampliação do Terminal de Passageiros e Sistema } \\
\text { Viário. }\end{array}$ \\
\hline \multirow{7}{*}{$\begin{array}{l}\text { Mobilidade } \\
\text { urbana }\end{array}$} & $\begin{array}{llll}\begin{array}{l}\text { Requalificação do } \\
\text { Cândida }\end{array} & \text { Terminal Santa } \\
\end{array}$ & $\begin{array}{l}\text { Reforma, ampliação e requalificação do terminal e } \\
\text { melhoria do acesso de veículos e pedestres. }\end{array}$ \\
\hline & $\begin{array}{l}\text { BRT: Extensão da Linha Verde Sul e } \\
\text { Obras Complementares ra da } \\
\text { Requalificação do Corredor Marechal } \\
\text { Floriano }\end{array}$ & Liga a Linha Verde Sul ao Contorno Sul. \\
\hline & $\begin{array}{l}\text { Requalificação da } \\
\text { (inclusive acessos) }\end{array}$ & $\begin{array}{l}\text { Melhoria dos acessos à Rodoferroviária, abertura e } \\
\text { recuperação de vias e requalificação da edificação. }\end{array}$ \\
\hline & $\begin{array}{lccc}\text { Vias } & \text { de } & \text { Integração } & \text { Radial } \\
\text { Metropolitanas } & & \\
\end{array}$ & $\begin{array}{l}\text { Integração dos municípios de Pinhais e Colombo } \\
\text { com Curitiba. }\end{array}$ \\
\hline & $\begin{array}{l}\begin{array}{l}\text { Requalificação do Corredor Marechal } \\
\begin{array}{l}\text { Floriano } \\
\text { municipal) }\end{array}\end{array} \text { (governos estadual e } \\
\end{array}$ & $\begin{array}{l}\text { Ligação alternativa entre o aeroporto (São José dos } \\
\text { Pinhais) e o centro da cidade de Curitiba. }\end{array}$ \\
\hline & $\begin{array}{l}\text { Sistema Integrado de Monitoramento } \\
\text { (governos estadual e municipal) }\end{array}$ & $\begin{array}{l}\text { Implantação e modernização do sistema de } \\
\text { controle e monitoramento do tráfego de veículos } \\
\text { em Curitiba e alguns municípios da Região } \\
\text { Metropolitana. }\end{array}$ \\
\hline & $\begin{array}{l}\text { Corredor Aeroporto / Rodoferroviária } \\
\text { (governos estadual e municipal) }\end{array}$ & $\begin{array}{l}\text { Liga o aeroporto à Rodoferroviária e promove a } \\
\text { integração com o setor hoteleiro e o estádio. }\end{array}$ \\
\hline Estádio & $\begin{array}{l}\text { Reforma e Ampliação do Complexo } \\
\text { Esportivo Curitiba } 2014\end{array}$ & $\begin{array}{l}\text { Reforma e ampliação do estádio Joaquim Américo } \\
\text { Guimarães. }\end{array}$ \\
\hline Turismo & Ações de Infraestrutura do Turismo & $\begin{array}{l}\text { Sinalização turística, acessibilidade nos pontos de } \\
\text { turismo, implantação de CATs (Centros de } \\
\text { Atendimento ao Turista), etc. }\end{array}$ \\
\hline
\end{tabular}

Nota: A referência para os projetos é 2013.

Fonte: CGU (2013). 
Mesmo tendo um dos menores percentuais de participação quando comparado ao das demais cidades-sedes, isso não significa que os investimentos tenham sido pequenos. O acompanhamento da evolução dos recursos destinados às obras da Copa do Mundo de 2014 em Curitiba demonstra que apesar da quantidade de projetos diminuir ao longo dos últimos anos, a previsão de investimentos aumentou representativamente: de $\mathrm{R}$ \$ 705,39 milhões passou-se para $\mathrm{R} \$ 968$ milhões, ampliação de um pouco mais de 37\% (CGU 2012, 2013).

Todos os projetos apresentaram crescimento na previsão de investimentos, porém, alguns se destacaram, pois em apenas um ano, entre os anos de 2012 e 2013, o aumento foi superior a $50 \%$ (gráfico 1 ).

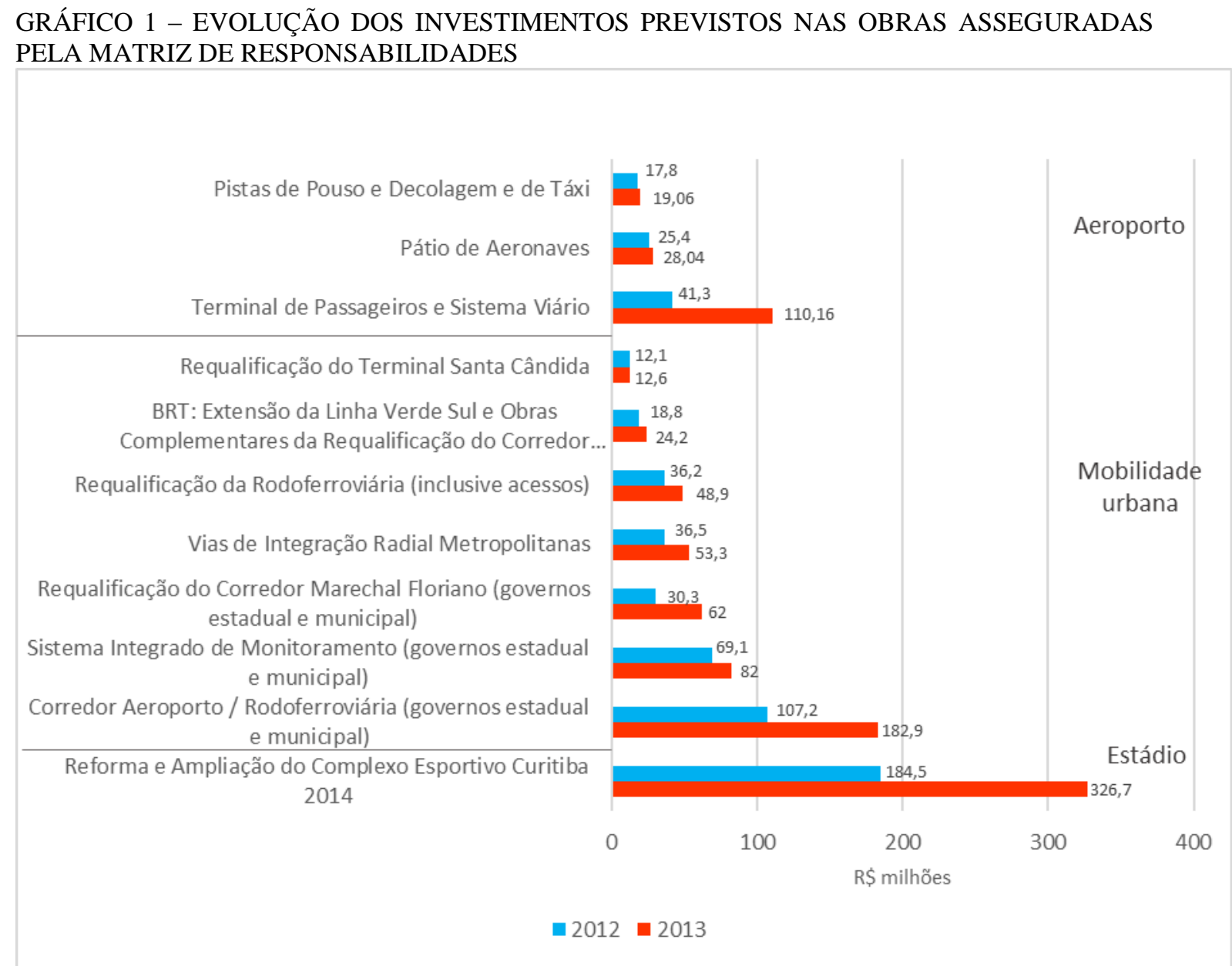

Fonte: CGU $(2012,2013)$. 
Nessa perspectiva se inserem as seguintes obras: Terminal de Passageiros e Sistema Viário, com ampliação de mais de 166\%; Requalificação do Corredor Marechal Floriano, aumento de mais de 104\%; e o Corredor Aeroporto-Rodoferroviária, incremento superior a 70\%. Além das obras citadas, o estádio Joaquim Américo Guimarães (Arena da Baixada), também apresentou ampliação bastante representativa na previsão de investimentos necessários, em torno de 77\%, passando de 184 milhões de reais em 2012 para 326 milhões no final de 2013.

Dentre as obras com aumento representativo nos custos está o Corredor Aeroporto-Rodoferroviária, que abrange os municípios de Curitiba e São José dos Pinhais, tendo em vista a localização do aeroporto neste último. Após as estimativas iniciais de investimentos necessários, foi incluída nesse projeto a construção de um viaduto estaiado na Avenida Coronel Francisco Heráclito dos Santos, em Curitiba, orçado em aproximadamente $\mathrm{R} \$ 84$ milhões.

Tido por técnicos e gestores como um novo "marco urbano", o viaduto estaiado insere-se em um contexto de continuidade da estratégia de city marketing presente na cidade, principalmente a partir da década de 1990. Localizado no Corredor Aeroporto-Rodoferroviária, o viaduto emerge como um marco simbólico da realização da Copa na cidade, além de evidenciar o alinhamento aos preceitos da arquitetura de grande impacto visual e pouco envolvimento com a realidade local, ou da estética em detrimento do funcional. O viaduto também revela a opção por empreendimentos pontuais, os quais, segundo Harvey (1996), costumam tornar-se o foco da atenção pública e política, a ponto de desviar atenção e até recursos de outros problemas mais importantes e que envolvem a cidade como um todo.

E é nessa perspectiva, dos empreendimentos pontuais, que se pode caracterizar todos os projetos relacionados à Copa do Mundo de 2014 em Curitiba. Apenas algumas porções da cidade foram priorizadas no acolhimento dos projetos, demonstrando a preocupação maior com a realização do evento, contrariamente ao afirmado durante o período de candidatura de Curitiba, ou seja, de que ocorreriam grandes transformações que afetariam positivamente o cotidiano da população. Essa contradição entre o afirmado e o que de fato caracterizou a preparação para o evento é corroborada quando se verifica que do total de investimentos previstos na Matriz de Responsabilidades para

\footnotetext{
${ }^{8}$ Segundo declarações de técnicos responsáveis pelas obras da Copa, em audiências públicas realizadas em Curitiba no ano de 2011.
} 
Curitiba, $82,2 \%$ se referem a obras relacionadas diretamente ao evento, seja na chegada, partida ou recepção de turistas, seja na realização do jogo ou ainda nos caminhos entre aeroporto, rodoviária e estádio. Tal configuração reforça o Corredor AeroportoRodoferroviária como eixo privilegiado, no qual se concentraram as principais intervenções preparativas para a Copa.

As obras nesse corredor, que se constitui como a principal ligação entre o centro de Curitiba e o aeroporto Afonso Pena, configuram-se, assim, como o reforço ao acesso para aqueles que chegam/saem de Curitiba, portanto, revela a relação da cidade com seu exterior e os benefícios voltados mais para fora da cidade que para seu interior.

\section{CONSIDERAÇÕES FINAIS}

A análise sobre os ganhos relacionados aos megaeventos tende a ser superestimada, como mostraram os casos da África do Sul e Japão/Coreia do Sul. Mesmo nos exemplos utilizados como paradigma de sucesso, tal como o caso da Alemanha em 2006, a literatura demonstra que em curto prazo os benefícios econômicos foram quase inexpressivos, ante as vultosas quantias de investimento público. Quando se pensa no exemplo sul-africano tais constatações tornam-se ainda mais relevantes, já que, os impactos sociais da priorização de investimentos em áreas como a de infraestrutura, significaram menos investimentos em políticas sociais.

Com relação ao montante dos investimentos previstos no Brasil, verificou-se grande disparidade na distribuição entre as regiões e entre os investimentos por setor.

Em Curitiba a reduzida participação nos investimentos evidenciou uma situação que é contrária ao apregoado pelos governantes, ou seja, de que a Copa do Mundo é um excelente momento para grandes transformações e desenvolvimento urbano e econômico. A localização dos investimentos demonstra que grande parte das obras de mobilidade urbana teve como principal objetivo garantir a ligação do aeroporto ao estádio e que, apesar de importante, não é capaz de, sozinha, solucionar problemas mais generais de circulação na cidade.

Conclui-se, portanto, que priorizar grandes eventos como meio de se sobressair num contexto em que a ideologia da competitividade impera, não se tem mostrado 
como uma alternativa viável para a solução de problemas urbanos, ao contrário, o modelo de cidade e de urbanismo que emerge sob tal perspectiva, tem apresentado resultados marcadamente acentuadores das desigualdades, já que ao mesmo tempo em que parcelas dos espaços são renovados em ritmo intenso e a prazo fixo, as receitas públicas e as políticas sociais ficam diretamente comprometidas, estas últimas principalmente em razão da inversão de prioridades e da necessidade de responder às demandas impostas pelo megaevento, mais que as urgências da sociedade local.

\section{REFERÊNCIAS}

AMATO, C. Weighing the World Cup's worth. Times Live, Johannesburg, Agosto de 2010. Disponível em:

$<$ http://www.timeslive.co.za/business/article615086.ece/Weighing--the--World--Cups-worth>. Acesso em: 05/02/2011.

ANDRANOVICH, G.; BURBANK, M. J.; HEYING, C. H. Olympic Cities: lessons learned form mega-event politics. Journal of Urban Affairs, v. 23, n. 2, p. 113-131, 2001.

ARAÚJO, T. Projeto desenha a Curitiba de 2014. Gazeta do Povo, Curitiba, 15/03/2009. Disponível em:

<http://www.gazetadopovo.com.br/esportes/conteudo.phtml?tl=1\&id=867135\&tit=Proj eto-desenha-a-Curitiba-de-2014>. Acesso em: 20/10/2013.

ASCHER, F. Os novos princípios do urbanismo. São Paulo: Romano Guerra, 2010.

BAADE, R.; MATHESON, V. The Quest for the Cup: assessing the economic impact of the world cup. Regional Studies, Seaford, v. 38, n. 4, p. 343-354, 2004.

BETARELLI JR; DOMINGUES, E.; MAGALHÃES, A. Quanto vale o show? Impactos econômicos dos investimentos da Copa o Mundo 2014 no Brasil. Estudos Econômicos (USP. Impresso), v. 41, p. 409-439, 2011.

BOND, P.; COTTLE, E. Economic Promises and Pitfalls of South Africa's World Cup. In: COTTLE, E. (Edit.). South Africa's World Cup: a legacy form whom? KwalaZulu-Natal: University of KwalaZulu-Natal Press, 2011. 
BRASIL. Resolução GECOPA n. 25, de 5 de novembro de 2013. Diário Oficial da República Federativa do Brasil, Brasília, DF, n. 228, p.100, 25 nov. 2013. Seção 1.

CBF - Confederação Brasileira de Futebol. Disponível em: 〈http://www.cbf.com.br/>. Acesso em: 30/06/2013.

CGU - Controladoria-Geral da União. Matriz de Responsabilidades. 2011. Disponível em: <http://www.transparencia.gov.br/copa2014/matriz/>. Acesso em: novembro de 2012 .

CGU - Controladoria-Geral da União. Matriz de Responsabilidades. 2012. Disponível em: <http://www.transparencia.gov.br/copa2014/matriz/>. Acesso em: novembro de 2012.

CGU - Controladoria-Geral da União. Matriz de Responsabilidades. 2013. Disponível em: <http://www.transparencia.gov.br/copa2014/matriz/>. Acesso em: novembro de 2012.

COTTLE, E. Scoring an Own Goal? The Construction Workers'2010 World Cup Strike. In: __ (Edit.). South Africa's World Cup: a legacy form whom? KwalaZuluNatal: University of KwalaZulu-Natal Press, 2011.

FIFA - FEDERAÇÃO INTERNACIONAL DE FUTEBOL. Estádios de Futebol Recomendações e Requisitos Técnicos. 5. ed. Suiça: FIFA, 2011. Disponível em: <http://pt.fifa.com/mm/document/tournament/competition/01/37/17/76/p_sb2010_stadi umbook_ganz.pdf $>$.

GRANT THORNTON. Updated economic impact of the 2010 FIFA World Cup. Grant Thornton Strategic Solutions: South Africa, April, 2010. Disponível em: <http://kzntopbusiness.co.za/site/user_data/files/Grant_Thornton_updated_2010_econo mic_impact_22April2010.pdf >. Acesso em: 30/03/2012.

HARVEY, D. Do gerenciamento ao empresariamento: a transformação da administração urbana no capitalismo tardio. Espaço \& Debates: Revista de Estudos Regionais e Urbanos, São Paulo, n. 39, p. 48-64, 1996.

O Enigma do Capital e as Crises do Capitalismo. São Paulo: Ed. Boitempo, 2011.

IBGE - Instituto Brasileiro de Geografia e Estatística. Contas Regionais do Brasil 2011. Contas Nacionais n. 40, Rio de Janeiro: IBGE, 2013a. 
Produto Interno Bruto dos Municípios 2011. Contas Nacionais n. 41, Rio de Janeiro: IBGE, 2013b.

LOGAN, J. R.; MOLOTCH, H. L. The City as a growth machine. In: FAINSTEIN, S.; CAMPBELL, S. (org.).Urban Theory. Oxford: Blackwell, 1996.

MEANING, W. One year later: a re-appraisal of the economics of the 2006 soccer world cup. Hamburg Contemporary Economic Discussions Papers. Hamburg: Universität Hamburg, n. 10, 2007. Disponível em: <http://www.unihamburg.de/economicpolicy/hced.html>. Acesso em: 20/03/2013.

MIKOS, A. L. Prefeitura desiste oficialmente de executar o Corredor Cândido de Abreu. Gazeta do Povo, Curitiba, 26/03/2013. Disponível em: <http://www.gazetadopovo.com.br/copa2014/curitiba/conteudo.phtml?id=1357293>. Acesso em novembro de 2013.

QUEIRÓS, M. Impressões de uma geógrafa portuguesa sobre as transformações recentes de Barcelona. Resposta ao desafio de Horacio Capel. Biblio 3W. Revista Bibliográfica de Geografía y Ciencias Sociales, Universidad de Barcelona, n. XV, n. 850, 2009. Disponível em: <http://www.ub.es/geocrit/b3w-850.htm>. Acesso em: $15 / 08 / 2011$.

Barcelona(s): cidade dos projectos ou projectos da cidade? Finisterra, Lisboa, XLV, 90, 2010. Disponível em <http://www.ceg.ul.pt/finisterra/>. Acesso em: $15 / 08 / 2011$.

SÁNCHEZ, F. A Reinvenção das Cidades para um mercado mundial. Chapecó, Santa Catarina: Argos, 2010.

TAAL, M. Their Cup Runneth Over: Construction Companies and the 2010 FIFA World Cup. In: COTTLE, E. (Edit.). South Africa's World Cup: a legacy form whom? KwalaZulu-Natal: University of KwalaZulu-Natal Press, 2011.

TCU - Tribunal de Contas da União. O TCU e a Copa do Mundo de 2014: relatório de situação: novembro de 2011. Brasília: TCU, 2011.

O TCU e a Copa do Mundo de 2014: relatório de situação: novembro de 2012. Brasília: TCU, 2012.

VAINER, C. A Cidade da Exceção: Reflexões a partir do Rio de Janeiro. In: XIV ENCONTRO NACIONAL DA ANPUR. Rio de Janeiro. Anais..., 2011. 
VOIGT, K. Is there a World Cup economic bounce. World Cup South Africa 2010: CNN, 11/06/2010.

Recebido em: 26-11-2013.

Aprovado em: 26-12-2013. 